\title{
RETENTION AND FATIGUE RESISTANCE OF PEEK AND ACETAL THERMOPLASTIC RESIN CLASPS
}

\author{
Azza A. El- Segai* and Muhammad Abbas**
}

\begin{abstract}
Aim; The objective of this study was to evaluate the retentive force of clasps made from two thermoplastic resins by the insertion/removal test simulating two years.

Methods: Over standardized premolar and molar metal crowns 36 clasps were fabricated, including 18 clasps $(1.5 \mathrm{~mm}$ thick) from each of the following thermoplastic resins: polyetheretherketon (PEEK) and polyoxymethylene (POM). Each clasp assembly was subjected to an insertion/removal test on its abutment crown. Retention of each clasp at pre-test (Baseline) and after insertion/removal cycling intervals (360, 730, 1080, 1440, 2116 and 2880 cycles by chewing simulator) were measured by applying withdrawal force to it using universal testing machine. To analyze the retention over the course of insertion/removal test, retention was measured every 360 cycles. Data were statistically analyzed using 3-way ANOVA $(\alpha=0.05)$.
\end{abstract}

Results. PEEK Resin material group recorded statistically significant higher mean value than Acetal material group mean value $(\mathrm{P}=0.0013<0.05)$. Molar abutment group recorded statistically non-significant higher mean value than premolar abutment group mean value $(\mathrm{P}=0.0620>0.05)$. Retention decreased significantly as indicated by three-way ANOVA $(\mathrm{P}=0.007<0.05)$.

Conclusion: Retention forces of PEEK clasps were clinically acceptable, and superior to retention forces of Acetal clasps. However, both the retention of adequately designed resin clasps might be enough for clinical use. Clasps made of PEEK showed the more promising retentive force with a non-fracture tendency at tooth undercut.

KEYWORDS; PEEK, Acetyl, Clasps, Insertion Force, Removable Partial Denture

\section{INTRODUCTION}

A major esthetical problem with partial removable dental prostheses (PRDPs) is the display of the clasp assemblies. Many methods have been used to overcome the esthetic problem such as etching the clasp arm and coat it with a layer of tooth-color resin, using lingual retention design, or proximal undercuts ${ }^{(1)}$

Retentive clasp arms must be flexible and should retain the PRDP satisfactorily. In addition,

* Assistant Professor, Removable Prosthodontics Department, Faculty of Dentistry, Tanta University, Egypt.

** Assistant Professor, Dental Biomaterials Department, Faculty of Dental medicine, Al-Azhar University, Egypt 
clasps should not unduly stress abutment teeth or be permanently distorted during service ${ }^{(2)}$. Various metallic materials have been used to fabricate the clasps of PRDPs and the physical properties of these materials have been examined. The most common alloys used for clasps are cobalt-chromium $(\mathrm{CoCr})$ alloys ${ }^{(3)}$. For the clasps to be retentive they must be flexible and retain the PRDPs satisfactorily ${ }^{(4)}$. They donot have to transmit excess stress to the abutment tooth. Previous studies have shown that clasps made of more elastic materials present better resistance to loss of retention ${ }^{(5)}$. On the other hand, if the clasps are excessively flexible, they may not provide adequate retention when positioned on the abutment tooth ${ }^{(6)}$.

Polyoxymethylene (POM) also known as acetal resin, an injection-molded resin has been introduced as an alternative to conventional Polymethylemethacrylate (PMMA). Polyoxymethylene is formed by the polymerization of formaldehyde. The homopolymer, polyoxymethylene is a chain of alternating methyl groups linked by an oxygen molecule. It has a relatively high proportional limit with little viscous flow enabling it to behave elastically over a great enough range to be used as a material for clasp construction ${ }^{(7)}$.

PEEK (polyetheretherketon) is part of a relatively new family of high temperature thermoplastic polymers. These polymers have great physical resistance, hydrological stability and rigidity, with a modulus of elasticity similar to bone. It is a main aromatic chain, connected with ketone and ether groups ${ }^{(8)}$. In medicine, PEEK has been shown to be an excellent substitute for titanium in different therapeutic applications, and in dentistry as a temporary implant abutment ${ }^{(5)}$.

The low modulus of elasticity of the thermoplastic resins presents superior flexibility compared to the conventional Cr-Co alloys ${ }^{(9)}$. The progressive loss of mechanical properties after repeated loads is an important consideration for the choice of materials. Although, clasp fatigue is based on recurrent deflection by repeatedly inserting and removing the prostheses $^{(10)}$.

There are few studies that examined mechanical properties of thermoplastic resins to determine the appropriate design for PRDP clasp ${ }^{(11)}$. However, to our knowledge there are little studies evaluating the use of PEEK as clasp materials. Therefore, this in-vitro study explored the retentive force of two thermoplastic resin clasps after repeated insertion and removal on two different abutment teeth. The null hypothesis was that there would be no difference in the retentive force between resin clasps or abutment teeth.

\section{MATERIALS AND METHODS}

Two thermoplastic resins (PEEK and Acetal) were evaluated in this study. Materials used are presented in Table 1.

TABLE (1) Materials used for clasp fabrication.

\begin{tabular}{|c|c|c|c|}
\hline $\begin{array}{c}\text { Brand } \\
\text { name }\end{array}$ & Composition & Manufacturer & Batch number \\
\hline PEEK & Polyetheretherketon & $\begin{array}{c}\text { Bredent, } \\
\text { Senden, } \\
\text { Germany }\end{array}$ & 540XS016901 \\
\hline Acetal & $\begin{array}{c}\text { Polyoxymethylene } \\
\text { (POM) }\end{array}$ & $\begin{array}{c}\text { Thermoflex } \\
\text { Acetal Resin } \\
\text { Densply UK }\end{array}$ & 01065 \\
\hline
\end{tabular}

\section{Abutment fabrication}

An artificial maxillary first premolar and molar (KaVo, Germany) were embedded in autopolymerizing acrylic resin (Acrostone, Cairo, Egypt) using custom-made copper holders with a diameter of $15 \mathrm{~mm}$ and $20 \mathrm{~mm}$ high. The teeth were prepared for a surveyed complete metal crown. The prepared teeth were dublicated twice using a rubber impression material (Impregum Penta $\mathrm{H}$ 
and L; 3M Espe, Germany). The impressions were poured in Type IV stone (GC, Belgium), and a complete crown was waxed on each preparation (Crowax; GmbH, Germany).The waxed crowns were surveyed to provide an undercut of $0.25 \mathrm{~mm}$ Occlusal rests, $2.5 \mathrm{~mm}$ long, $2.5 \mathrm{~mm}$ wide, and 2 $\mathrm{mm}$ deep, were placed dismally for premolar and mesially for molar. Mesial and lingual guide planes, two thirds the length of the crown, were prepared with a surveyor blade to standardize the path of insertion. The waxed 2 crowns were duplicated with silicon material (Speedy, Augsburg, Germany), and then 18 premolar crowns and 18 molar crowns were made by inserting heated liquid wax into the silicone mold. Then the crowns were cast in $\mathrm{Co}-\mathrm{Cr}$ alloy (Wironit 99; Bego, Bremen, Germany). After fitting and finishing, the crowns were cemented inplace on the abutments with zinc phosphate cement (Hoffmann, Berlin, Germany). The guide planes were evaluated for parallelism.

\section{Clasp fabrication}

To standardize the position of clasp arm undesirable undercut areas were blocked out with the sculpturing wax (Crowax, Germany) with approximately $2 \mathrm{~mm}$ surrounding thickness. Impressions of each model were made in rubber impression material (Impregum Penta $\mathrm{H}$ and L) with custom impression trays. Each impression was poured with Type IV dental stone (GC Fujirock EP, GC), to make refractory casts for the thermoplastic resin clasps. For fabrication of the $1.5 \mathrm{~mm}$ thick thermoplastic resin clasps straight semicircular clasp patterns (Wax patterns, Omnident, Germany) (1.5 $\mathrm{mm} \times 3 \mathrm{~mm}$ ) were used. The previously described wax sprue was connected to the residual ridge base parallel to the path of insertion using a surveyor. The parameters for the injection procedures have been set according to the manufacturers

\section{PEEK samples construction}

Wax patterns of clasp were constructed, and sprues were attached. The assembly was attached to the investment ring then invested using special investment material for 2 press (Bredent-SendenGermany), after material setting the mould was then heated to $630^{\circ} \mathrm{C}$ then temperature was gradually increased by rate of $80 \mathrm{C} / \mathrm{min}$ until it reached $850^{\circ} \mathrm{C}$ in a preheated oven (IBEX-dental oven-USA) for wax burnout for 60 minutes before starting the melting process. Granular PEEK-BioHPP thermoplastic (BioHPP (granulate) 20g-BredentSenden-Germany) material was placed in the melting channel. Then the ring was placed back into the preheated oven for 20 minutes at temperature $400^{\circ} \mathrm{C}$ to get a creamy molten material with uniform appearance indicating that the material was ready for pressing and injection pressure of 4 bar. By the end of the process the mould was allowed to cool for 35 minutes. The mould was then placed in water bath for 10 minutes then devesting was done first with scissors to remove the mould then using pneumatic devesting chisel. The fine blasting device was used to get the clasps.

\section{Acetal samples construction}

The acetal resin (Thermoflex Acetal Resin Densply UK) samples were prepared in accordance with manufacturer's instructions. The wax pattern of the clasp was flasked using special Aluminum flask (Thermopress flask, bredent GmbH, Germany) mold with Class IV type plaster (Marble Stone, Pressing Dental San Marino, Italy). Heated softened acetal resin was injected into the mold then curing was done at $215 \mathrm{C}^{0}$ for 25 minutes and injection pressure of 4 bars. After curing the samples were deflasked, finished and polished using thermal resin finishing burs (Abraso-Star K 50, Bredent GmbH, Germany) and pumice at low speed then finally buffed with swans down mop for fine luster.

\section{Testing conditions}

Each clasp and its model were mounted on a Universal testing machine (Instron® 3345, Instron 
Co. Ltd, Norwood, MA) as shown in figure (1). Retention of each clasp at pre-test (Baseline) was measured by applying withdrawal force to it by this machine at $5 \mathrm{~mm} / \mathrm{min}$.

To perform the fatigue test, through removal and insertion cycling, ROBOTA chewing simulator integrated with thermo-cyclic protocol operated on servo-motor (Model ACH-09075DC-T, AD-TECH TECHNOLOGY CO., LTD., GERMANY) was used as shown in figure (2). The machine allows the placement of the clasp to its predetermined terminal position and its subsequent removal from the abutment crown, thus simulating the placement and removal of a PRDP. The models with the crowns were mounted in the chewing simulator. Each clasp

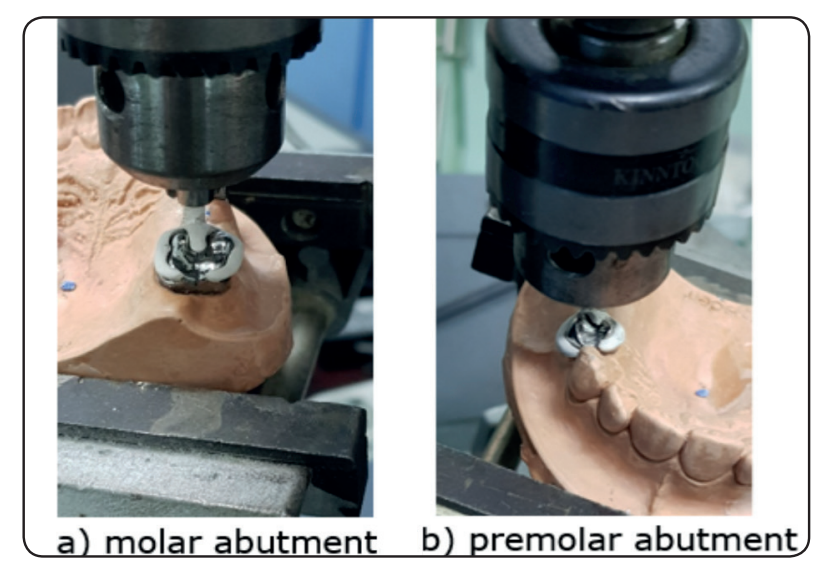

Fig. (1) Clasps/abutment mounted on testing machine for retentive force test

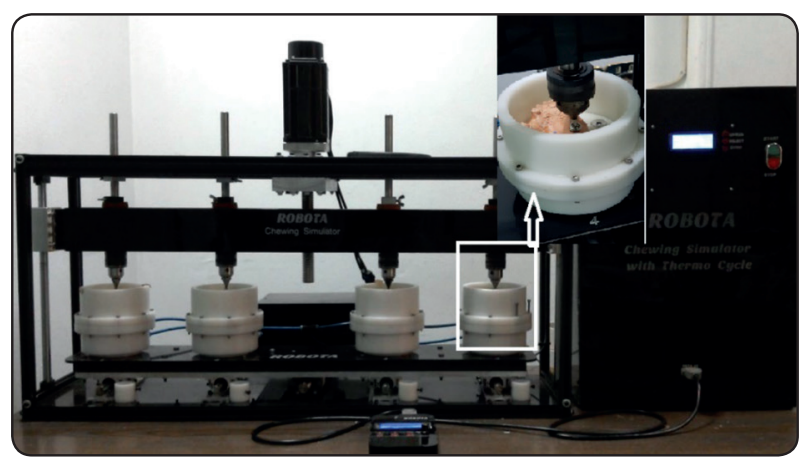

Fig. (2) Clasps/abutment mounted on chewing simulator for removal-insertion cycling test specimen was then placed on the corresponding abutment crown and fixed to the upper part of machine with vertical rod. The test conditions were maintained at room temperature $\left(25 \pm 2^{\circ} \mathrm{C}\right)$ and wet condition. Removal and insertion cycling of clasps was carried out for 360, 730, 1080, 1440, 2116 and 2880 cycles (corresponding to $3,6,9$, 12,18 and 24 months of simulated clinical use of a RPD) to simulate the fatigue resistance test ${ }^{(12)}$. Using Universal testing machine running at $5 \mathrm{~mm} /$ min the retention force was determined for the clasp at 360, 730, 1080, 1440, 2116 and 2880 cycles, and recorded by the computer software (Bluehill, Instron instruments).

\section{Statistical analysis}

The data of the retentive force magnitudes in Newton at different intervals were collected and tabulated. The data were subjected to statistical analysis using 3-way-ANOVA test and t-test. The results were analyzed using Graph Pad Instat (Graph $\mathrm{Pad}$, Inc.) software for windows. A value of $\mathrm{P} \leq 0.05$ was considered statistically significant.

\section{RESULTS}

Retention (N) results (Mean $\pm \mathrm{SD}$ ) for both groups as function of abutment and different interval are summarized in table (2) and figure (3).

Effect of clasp material; regardless to abutment or different intervals totally it was shown that PEEK Resin material group recorded higher mean value than Acetal material group mean value. The difference between both materials groups means values was statistically significant as indicated by three-way ANOVA $(\mathrm{P}=0.0013<0.05)$.

Effect of abutment type; regardless to material or different intervals totally it was shown that molar abutment group recorded higher mean value than premolar abutment group mean value. The difference between both abutment groups means values was statistically non-significant as indicated by three-way ANOVA $(\mathrm{P}=0.0620>0.05)$. 
Effect of evaluation interval; regardless to material or abutment type totally it was shown that retention decreased significantly as indicated by three-way ANOVA $(\mathrm{P}=0.007<0.05)$.

TABLE (2) Means and standard deviations for both groups as function of abutment and different intervals

\begin{tabular}{|c|c|c|c|c|c|}
\hline \multirow{2}{*}{\multicolumn{2}{|c|}{ Variables }} & \multicolumn{2}{|c|}{ Peek } & \multicolumn{2}{|c|}{ Acetal } \\
\hline & & Premolar & Molar & Premolar & Molar \\
\hline \multirow{7}{*}{ 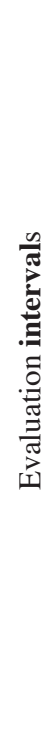 } & Baseline & $\begin{array}{l}39.19 \\
\pm 0.03\end{array}$ & $\begin{array}{l}62.27 \\
\pm 6.58\end{array}$ & $\begin{array}{r}26.85 \\
\pm 3.18\end{array}$ & $\begin{array}{r}18.89 \\
\pm 1.27\end{array}$ \\
\hline & $\begin{array}{c}360 \\
\text { cycles }\end{array}$ & $\begin{array}{r}15.19 \\
\pm 0.11\end{array}$ & $\begin{array}{r}49.02 \\
\pm 3.79\end{array}$ & $\begin{array}{c}5.09 \\
\pm 0.81\end{array}$ & $\begin{array}{r}12.04 \\
\pm 1.22\end{array}$ \\
\hline & $\begin{array}{c}720 \\
\text { cycles }\end{array}$ & $\begin{array}{r}14.45 \\
\pm 0.56\end{array}$ & $\begin{array}{r}35.56 \\
\pm 2.68\end{array}$ & $\begin{array}{c}4.27 \\
\pm 0.06\end{array}$ & $\begin{array}{r}11.63 \\
\pm 3.45\end{array}$ \\
\hline & $\begin{array}{c}1080 \\
\text { cycles }\end{array}$ & $\begin{array}{r}10.54 \\
\pm 0.87\end{array}$ & $\begin{array}{r}28.83 \\
\pm 4.25\end{array}$ & $\begin{array}{c}3.75 \\
\pm 0.05\end{array}$ & $\begin{array}{r}11.28 \\
\pm 0.78\end{array}$ \\
\hline & $\begin{array}{l}1440 \\
\text { cycles }\end{array}$ & $\begin{array}{c}7.73 \\
\pm 2.06\end{array}$ & $\begin{array}{r}22.57 \\
\pm 1.35\end{array}$ & $\begin{array}{c}3.65 \\
\pm 0.05\end{array}$ & $\begin{array}{c}6.71 \\
\pm 1.53\end{array}$ \\
\hline & $\begin{array}{l}2160 \\
\text { cycles }\end{array}$ & $\begin{array}{c}6.91 \\
\pm 0.59\end{array}$ & $\begin{array}{r}9.54 \\
\pm 1.16\end{array}$ & $\begin{array}{c}2.67 \\
\pm 0.34\end{array}$ & $\begin{array}{r}4.06 \\
\pm 0.31\end{array}$ \\
\hline & $\begin{array}{l}2880 \\
\text { cycles }\end{array}$ & $\begin{array}{c}3.92 \\
\pm 1.23\end{array}$ & $\begin{array}{c}5.03 \\
\pm 0.81\end{array}$ & $\begin{array}{c}1.77 \\
\pm 1.05\end{array}$ & $\begin{array}{r}2.73 \\
\pm 0.63\end{array}$ \\
\hline
\end{tabular}

\section{DISCUSSION}

The demand for esthetic dental restorations has been increased due to emphasis on physical appearance in contemporary society (13). Polyetheretherketone (PEEK) is a synthetic, tooth colored polymeric material that has been used as a biomaterial in orthopedics for many years with observed mechanical properties, and adequate mechanical stability to justify the basic requirements in the restorative field as showed by recent studies ${ }^{(14,15)}$. A few studies have reported on the adequate retentive forces required for clasps retention ${ }^{(16,17)}$. One study stated that 3 to $7.5 \mathrm{~N}$ is the retentive force required for adequate retention and functioning of PRDPs, while another study found that $5 \mathrm{~N}$ could give an acceptable degree of retention ${ }^{(18)}$.

Thermoplastic clasps might achieve clinically acceptable retention at dimensions differing from those of metal clasps, possibly requiring thicker clasp to engage a deeper undercut. This is due to the relatively low rigidity of the thermoplastic resin (elastic modulus; 2.4 GPa for POM and 4.0 GPa for PEEK as compared to $240 \mathrm{GPa}$ for Co-Cr alloy) and may reduce the possibility of traumatic overloading $(1,11,19)$. The retentive force is dictated by tooth

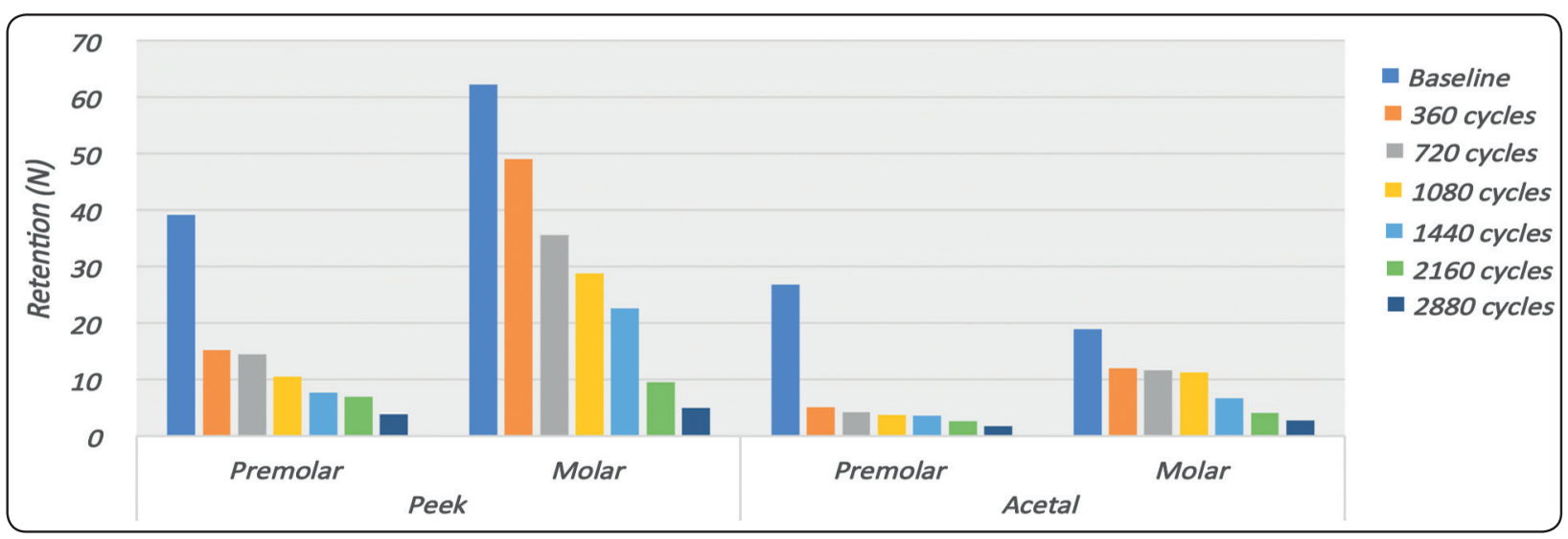

Fig. (3) Change in retentive forces for both groups as function of abutment and different intervals. 
shape and by clasp design. Tooth shape influences retention by determining the depth of undercut available for clasping ${ }^{(20)}$.However, difference between both abutment groups means values was statistically non-significant in this study.

In this study, every clasp had its own abutment, and this has reduced the opportunity of abutment wear, so that the retentive force could be measured more accurately. While in previous studies, clasp retentive forces were measured, and cyclic fatigue tests were performed on a single abutment tooth. $(21,22)$

Based on the results obtained in this study, the novel clasp made from PEEK material of $1.5 \mathrm{~mm}$ thick showed significantly higher retention force compared to Acetal claps, the null hypothesis was rejected. Loss of retention of the clasps due to fatigue resistance test was considered as a good indicator of permanent deformation of the clasps ${ }^{(3)}$. These agreed with Helal, et al. who reported that the clasp may lose its retention force as a result of multiple deflections ${ }^{(12)}$, and contradict with Meenakshi, et al. who showed that the retention force of acetal clasps did not decrease after cycling intervals while the Co-Cr clasps lost retention force within 730 cycles of insertion/removal and continued to lose retention force during the remaining intervals ${ }^{(23)}$. This may be explained by the method which is used to carry out the test.

It could be claimed that the two bulkier designs which used to make the thermoplastic clasps could prevent the self-cleaning functions and cause more plaque accumulation. However, several studies showed that if plaque control is established and a regular recall system with control, reinstruction and re-motivation is provided, removable partial dentures might not cause damage to the periodontium $(24,25)$. Shimura et al. found that the plaque formation on the buccal surface is not dependent on the type or placement of clasps and suggested to prepare the guide plane as close to the gingival margin as possible to reduce the plaque accumulation on the disto-proximal surface ${ }^{(26)}$. However, clinical studies are recommended to evaluate the effect of resin clasps on the plaque accumulation on the abutment teeth.

Limitations of this study include that the test was performed in a rigid system. Clinical conditions may not be the same due to the presence of periodontal ligament which allows physiological movement of natural teeth. Intra-oral insertion and removal paths usually differ since obtaining truly effective guide planes is conditioned by anatomical features. Additionally, patients can change the path used to move the denture at each insertion and/or removal cycle, producing greater loads on the tooth, thus leading to permanent clasp defects in a short time. Therefore, further studies are needed, in conditions closer to clinical situations.

\section{CONCLUSION}

These results reveal that thermoplastic resins could be used in the construction of clasps for PRDPs, as they offer adequate retention for PRDP even after simulated years of use. The results show that PEEK thermoplastic material could be used in the fabrication of clasps for PRDPs, as they provide adequate retention to engage a deeper undercut area with thicker clasp even after simulated time of use.

\section{REFERENCES}

1. Tannous F, Steiner M, Shahin R, Kern M. Retentive forces and fatigue resistance of thermoplastic resin clasps. Dental Mater 2012;28:273-8.

2. Kotake M, Wakabayashi N, Ai M, Yoneyama T, Hamanaka H. Fatigue resistance of titanium-nickel alloy cast clasps. Int J Prosthodont 1997;10:547-52.

3. Abd-Elrahman IA, Helal MA, Saqar HM, Abas M. Evaluation of Fatigue Resistance of Acetal Resin and Cobalt-Chromium Removable Partial Denture Clasps. An In-vitro Study: Part 1. J Dent Oral Care Med 2016;2(3): 1-6. 
4. Osada H., Shimpo H., Hayakawa T., Ohkubo C. Influence of thickness and undercut of thermoplastic resin clasps on retentive force. Dent Mater J. 2013;32:381-389.

5. Alvarez S, Escuin T, Claremont R, Ascaso C. Preliminary Study to compare the insertion/removal force of PEEK and Co-Cr clasps. Open Journal of Dentistry and Oral Medicine 2017;5(2): 11-19.

6. Tarek M., Osama A. B., Magdy M. B. Comparison between Acetal Resin and Cobalt-Chromium Removable Partial Denture Clasp Retention: An in vitro Study. J od Prost Res. 2013;3:50-56.

7. Fitton JS, Davies EH, Howlett JA, Pearson GJ. The physical properties of a polyacetal denture resin. Clin Mater 1994;17:125-9

8. Kurtz SM, Devine JN. PEEK biomaterials in trauma, orthopedic, and spinal implants. Biomaterials 2007; 28:4845-69.

9. Kawara M., Iwata Y., Iwasaki M., Komoda Y., Iida T., Asano T., Komiyama O. Scratch test of thermoplastic denture base resins for non-metal clasp dentures. J of Prost Res. 2014;58:35-40.

10. Bayer S., Komor N., Kramer A., Albrecht D., MericskeStern R., Enkling N. Retention force of plastic clips on implant bars: a randomized controlled trial. Clinic Oral Implants Res 201223:1377-1384.

11. Turner JW, Radford DR, Sherriff M. Flexural properties and surface finishing of acetal resin denture clasps. J Prosthodont 1999;8:188-95.

12. Helal MA, Baraka OA, Sanad ME, Al-Khiary Y, Ludwig $\mathrm{K}$, et al. Effect of clasp design on retention at different intervals using different abutment materials and in a simulated oral condition. J Prosthodont 2014;23: 140-5.

13. Chu $\mathrm{CH}$, Chow TW. Esthetic designs of removable partial dentures. Gen Dent. 2003;51: 322-4.

14. Stawarczyk, B.; Jordan, P.; Schmidlin, P.R.; Roos, M.; Eichberger, M.; Gernet, W.; Keul, C. PEEK surface treatment effects on tensile bond strength to veneering resins. J. Prosthet. Dent. 2014; 112: 1278-1288.

15. Uhrenbacher, J.; Schmidlin, P.R.; Keul, C.; Eichberger,
M.; Roos, M.; Gernet, W.; Stawarczyk, B. The effect of surface modification on the retention strength of polyetheretherketone crowns adhesively bonded to dentin abutments. J. Prosthet. Dent. 2014; 112: 1489-1497.

16. Sato Y, Tsuga K, Abe Y, Asahara S, Akagawa Y. Finite element analysis on preferable I-bar clasp shape. J Oral Rehabil2001;28:413-7.

17. Frank RP. \& Nicholls JI. A study of the flexibility of wrought wire clasps. J. Prosthet.Dent.1981;45, 259-267.

18. Muhsin SA, Wood DJ, Johnson A, Serena N, Hatton PV. Effects of novel polyetheretherketone (PEEK) clasp design on retentive force at different tooth undercuts. The Journal of Oral and Dental Research 5 2018;2: 13-25.

19. KURTZ, S. M. Peek Biomaterials Handbook, William Andrew Publishing. 2011.

20. Vallittu PK, Kokkonen M. Deflection fatigue of cobaltchromium, titanium, and gold alloy cast denture clasp. J Prosthet Dent 1995;74: 412-19.

21. Rodrigues R.C., Ribeiro R.F., de Mattos Mda G., and Bezzon O.L. Comparative study of circumferential clasp retention force for titanium and cobalt-chromium removable partial dentures. J Prosthet Dent 2002; 88:290-6.

22. Kim D., Park C., Yi Y., and Cho L. Comparison of cast Ti-Ni alloy clasp retention with conventional removable partial denture clasps. J Prosthet Dent 2004; 91:374-82.

23. Meenakshi A, Gupta R, Bharti V, Sriramaprabu G, Prabhakar R. An Evaluation of Retentive Ability and Deformation of Acetal Resin and Cobalt Chromium Clasps. JCDR 2016;10: ZC37-41.

24. Bergman B, Hugoson A, Olsson CO. A 25 year longitudinal study of patients treated with removable partial dentures. $\mathrm{J}$ Oral Rehabil1995;22:595-9

25. Mine K, Fueki K, Igarashi Y. Microbiological risk for periodontitis of abutment teeth in patients with removable partial dentures. J Oral Rehabil2009;36:696-702.

26. Shimura Y, Wadachi J, Nakamura T, Mizutani H, Igarashi Y. Influence of removable partial dentures on the formation of dental plaque on abutment teeth. J Prosthodont Res 2010;54:29-35 